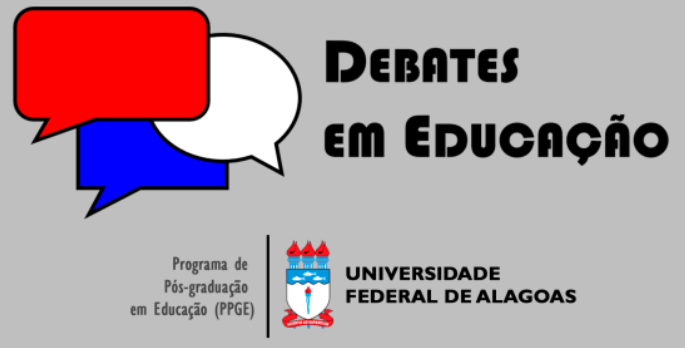

ISSN Eletrônico 2175-6600

Vol. 10 | No. 21 | Maio/Ago. | 2018

Adelino Francklin (9) iD

Universidade Federal de São Carlos (UFSCar) afrancklin@uol.com.br

\section{AS IMPLICAÇÕES DO PROGRAMA CHOQUE DE GESTÃO PARA O TRABALHO DOCENTE NA REDE ESTADUAL MINEIRA}

\section{RESUMO}

A presente pesquisa visa analisar os efeitos do Programa Choque de Gestão (CG), entre 2003 e 2014, para o trabalho docente dos professores secundários da Rede Pública Estadual de Ensino de Minas Gerais (REE/MG). Justifica-se pelo fato de haver indícios de intensificação e precarização do trabalho docente devido às medidas deste programa de governo. O levantamento bibliográfico foi realizado por meio de buscas de artigos científicos, dissertações de mestrado e teses de doutorado pelo Google Acadêmico, site de periódicos da Scielo, banco de teses da CAPES e em bibliotecas universitárias. A coleta de dados se deu por meio de entrevistas semiestruturadas com 5 professores secundários da REE/MG. A abordagem da pesquisa foi qualitativa. Os resultados apontaram a existência de meritocracia, performatividade, proletarização, intensificação e precarização no trabalho docente na REE/MG. Entre as considerações finais, constatou-se que as medidas do programa CG, nas três gerações, provocaram uma intensificação e precarização do trabalho docente na REE/MG em virtude das condições de trabalho dos professores secundários, como a responsabilização por resultados, a má remuneração e a sobrecarga de trabalho.

Palavras-chave: Intensificação. Precarização. Trabalho docente.

THE IMPLICATIONS OF THE SHOCK MANAGEMENT PROGRAM FOR TEACHING IN THE NETWORK OF THE STATE OF MINAS GERAIS

\begin{abstract}
The present research aims to analyze the effects of the Shock Management Program (CG), between 2003 and 2014, for the teaching work of secondary teachers of the State Public Network of Minas Gerais (REE / MG). It is justified by the fact that there are indications of intensification and precariousness of teaching work due to the measures of this government program. The bibliographical survey was carried out by means of scientific articles searches, master dissertations and doctoral theses by Google Academic, Scielo, CAPES thesis bank and university libraries. Data were collected through semi-structured interviews with 5 REE / MG secondary teachers. The research approach was qualitative. The results pointed out the existence of meritocracy, performativity, proletarianization, intensification and precarization in the teaching work in REE / MG. Among the final considerations, it was verified that the CG program measures, in the three generations, provoked an intensification and precariousness of the teaching work in REE / MG due to the working conditions of secondary teachers, such as accountability for results, poor remuneration and work overload.
\end{abstract}

Keywords: Intensification. Precariousness. Teaching Work.

Submetido em: 02/03/2018

Aceito em: 28/07/2018

DOI: $10.28998 / 2175-6600.2018 v 10 n 21 p 89-105$ 


\section{INTRODUÇÃO}

A expansão do modelo neoliberal tem provocado mudanças no ambiente de trabalho, na individualidade e tem estimulado um espírito de competitividade entre diversos profissionais.

O Banco Mundial (BM), que apresenta tendência neoliberal, tem financiado a educação básica nos países em desenvolvimento, além de estabelecer uma série de recomendações a serem implementadas na educação. Para Torres (1996, p. 126) “o BM transformou-se na principal agência de assistência técnica em matéria de educação para os países em desenvolvimento".

Apesar de assumir um modelo educativo essencialmente escolar, nota-se que, tanto nacional quanto internacionalmente, a política educativa proposta pelo BM concentra-se principalmente nas mãos de economistas. Por eles, "os professores (e seus sindicatos) são vistos como problema antes que recurso, 'insumo' educativo necessário, porém caro, complexo e difícil de lidar" (TORRES, 1996, p. 161). Tal visão revela-se preocupante, tendo em vista que "no Brasil, a profissão docente apresenta baixa atratividade em razão dos níveis de remuneração, das condições de trabalho e das expectativas oferecidas pelas carreiras" (OLIVEIRA, 2011, p. 26). Dessa forma, o modelo empresarial difundido pelos representantes do BM, que atendem apenas à lógica do lucro e da competição, colabora para a desvalorização ainda maior do magistério.

Em conformidade com as reformas neoliberais no âmbito mundial e nacional, o governo do estado de Minas Gerais (MG), representado por Aécio Neves (2003-2010) e Antonio Anastasia (2010-2014), ambos do PSDB, adotaram um programa de governo denominado Choque de Gestão (CG).

O programa CG foi criado em 2003 e teve como justificativa governamental o fato de que o estado de MG se encontrava em déficit e com graves problemas fiscais desde 1996, incluindo o atraso da remuneração dos servidores públicos. Deste modo, o programa visava cortar gastos e racionalizar a administração pública. O CG caminhou no mesmo sentido da performatividade ${ }^{1}$, que, segundo Ball (2004) "objetiva e mercantiliza o trabalho do setor público, e o trabalho com conhecimento (Knowledge-work) das instituições educativas transforma-se em 'resultados', 'níveis de desempenho', 'formas de qualidade'”. A performatividade se manifestou no estado de MG através de comparações entre as instituições e profissionais, através do apontamento de índices e do julgamento da

\footnotetext{
${ }^{1}$ Para Stephen Ball (2010), a performatividade é uma tecnologia, uma cultura, e um modo de regulação.
} 
competência de profissionais e de instituições. O que se esperava é a Qualidade Total nas escolas.

O governo de MG, no início do primeiro mandato do governador Aécio Neves (20032006), declarou "a intenção de retomar os então interrompidos contatos com os agentes internacionais de financiamento" (AUGUSTO, 2012, p. 700). Os empréstimos com o BM foram realizados, a exemplo do valor de 450 milhões de reais obtidos em 2012 para pagar dívida com a Companhia Energética de Minas Gerais (MACIEL, 2012). Destarte, verificouse a estreita relação entre o governo do estado de MG e o BM.

Destarte, adotou-se como objetivo conhecer e analisar quais os efeitos do programa CG sobre o trabalho docente na Rede Pública Estadual de Ensino de Minas Gerais (REE/MG), bem como certificar se os professores secundários ${ }^{2}$ da REE/MG passaram por um processo de intensificação e precarização devido às medidas do programa CG.

\section{MANIFESTAÇÕES DO PROGRAMA CHOQUE DE GESTÃO NA (REE/MG)}

No período de 2003 a 2014, o programa CG foi constituído por três gerações. A primeira geração, durante o primeiro mandato do governador Aécio Neves (2003-2006), ficou conhecida como Acordo de Resultados. A segunda geração, ocorrida durante 0 segundo mandato de Aécio Neves (2007-2010) foi denominada Estado para Resultados. Por fim, a terceira geração, na gestão do governador Antônio Anastasia (2010-2014) foi chamada de Estado Aberto e em Rede.

Uma série de recomendações do BM de tendências neoliberais pôde ser percebida claramente no programa CG, tais como a avaliação de desempenho dos docentes, aplicação de avaliações externas, aumento do número de alunos por classe, política de resultados, entre outras medidas (BANCO MUNDIAL, 1995).

Sobre as políticas neoliberais em educação, Hypolito (2011) defende que se pode identificar dois momentos inseparáveis, mas diferentes, que são a criação de rankings e as parcerias público-privadas.

Entre as políticas públicas de tendências neoliberais na educação, ocorre a aplicação de exames pelos governos estaduais para verificar o desempenho dos estudantes, que isentam o Estado de responsabilidades, ao passo que transferem total

\footnotetext{
2 A denominação professores secundários nesse artigo refere-se aos docentes que atuam no Ensino Fundamental II e Ensino Médio.
} 
responsabilização para as escolas e para os docentes. Desse modo, o que se constata é a adoção de um modelo gerencialista, caracterizado pela defesa da eficiência, pelas parcerias público-privadas, pela responsabilização, pelo estabelecimento de metas a serem atingidas, pela meritocracia e pela avaliação por desempenho. "Desta forma, se o ensino não vai bem, a responsabilidade não é do sistema, do Estado, mas do professor, que não sabe ensinar, do diretor que não sabe gerir" (AUGUSTO, 2011, p. 183).

Sobre o CG, Augusto (2010) alerta que por meio do Acordo de Resultados ampliouse de forma considerável a responsabilidade das escolas e dos professores da REE/MG.

Brito (2013) aponta que a remuneração dos docentes da REE/MG, no contexto do CG, foi abaixo da esperada em relação à lei do Piso Salarial a que se refere à Lei Federal n. 11.738/08. A partir da aprovação da Lei n. 18.975/2010, que estabeleceu a remuneração por subsídio, todas as vantagens foram incorporadas ao vencimento básico. Destarte, 0 plano de carreira dos docentes foi congelado.

A adoção de subsídios como forma de remuneração é prevista na Constituição Federal (CF) de 1988, no art. 39, e consiste em uma forma de remuneração caracterizada como parcela única, em que se incluem gratificações, abonos, entre outras de caráter remuneratório. "Nesse tipo de remuneração, todas as vantagens são incorporadas ao valor pago, não existindo plano de carreira, conforme mostra o artigo $2^{\circ}$ da Lei 11.738" (MACIEL; PREVITALI, 2011, p. 339). Conforme afirmam Duarte e Oliveira (2014, p. 85),

\begin{abstract}
Segundo o Sind-UTE/ MG, o modelo unificado de remuneração incorpora as gratificações por tempo de serviço ao vencimento inicial, desvalorizando este aspecto e descumprindo a Lei do Piso, uma vez que esta se trata do vencimento em início de carreira, sem contabilizar as gratificações. Além disso, de acordo com o Sind-UTE/MG, as recentes reformas diminuíram os percentuais de progressão e promoção na carreira, além de valorizarem de sobremodo as avaliações de desempenho individual e institucional.
\end{abstract}

O governo estadual de MG foi constantemente criticado por não pagar o Piso Salarial do Magistério Público (Lei 11.738/2008). Enquanto o governo mineiro alegava que pagava um valor acima do Piso Salarial ${ }^{3}$ para os docentes da educação básica, pelo fato de estabelecer o subsídio para carga horária de 24 horas (tendo em vista que o Piso Salarial foi definido para carga horária de 40 horas), havia críticas de que o governo estadual de MG incorporava todas as vantagens dos servidores públicos como somatória para atingir o Piso Salarial.

\footnotetext{
${ }^{3}$ Em 2014 o professor da REE/MG com Licenciatura Plena, nível I, grau A, recebia o subsídio de $R \$ 1455,30$ para 24 horas semanais no estado de MG, enquanto o piso salarial nacional era de $R \$ 1697,00$ para 40 horas semanais.
} 
Com a Lei Estadual nํ. 17.600, de 1ํㅡ de julho de 2008, surgiu o pagamento do Prêmio por Produtividade. Tratava-se de uma forma de bonificação para os servidores do estado de MG. O prêmio não era uma complementação salarial, mas sim, uma maneira de incentivar, por mérito, os servidores que conseguissem alcançar resultados satisfatórios nas metas pactuadas.

A caracterização como política de responsabilização neoliberal promovida pelo governo estadual de MG evidenciou-se por meio da ênfase nos índices apontados pelo Sistema Mineiro de Avaliação da Educação Pública (SIMAVE) e na Avaliação de Desempenho Individual (ADI). Conforme afirma Duarte (2013, pp. 109-110),

A política educacional engendrada no contexto do programa "Choque de Gestão" revela uma profunda preocupação com os resultados escolares. Centradas na lógica da busca pela eficácia do sistema de ensino, como caracterizado anteriormente, essa nova modalidade de gestão pressupõe a obrigação de resultados e amplia, de forma significativa, a responsabilidade dos estabelecimentos escolares e dos professores sobre estes. As metas e indicadores de desempenho envolvem o avanço dos alunos nos resultados das avaliações do Sistema Mineiro de Avaliação da Educação Pública (SIMAVE), entendidos como índices de qualidade da educação básica no Estado, na rede estadual de ensino.

O SIMAVE4 foi criado no ano 2000, por meio da Resolução no 104/2000 e visa identificar necessidades, problemas e demandas do sistema e das escolas, auxiliar no planejamento de ações em diferentes níveis e momentos que busquem a melhoria da educação da REE/MG.

O bom êxito ou não dos alunos no SIMAVE passou a estar atrelado à avaliação de desempenho do professor. Nas escolas em que havia bons resultados por parte dos alunos, os professores recebiam um prêmio produtividade maiores. Por outro lado, nas escolas em que não havia bom êxito nessa avaliação externa, recebiam prêmio produtividade menores. Essas medidas estavam contidas no Acordo de Resultados, definido através da Lei no 17.600/2008 destinada às escolas. Nota-se, com essa política de resultados, uma gestão meritocrática.

Os índices das escolas apontados pelo SIMAVE passaram a ser divulgados pelo site da Secretaria Estadual de Educação de Minas Gerais (SEE/MG), podendo ser consultados livremente. Em forma de gráficos, visualizavam-se os resultados das escolas por disciplina, como recomendável, intermediário e baixo. Além disso, estabeleciam paralelos do resultado da escola em relação à média do Estado, à média da Superintendência Regional de Ensino (SRE) e à média dos resultados da própria escola em anos anteriores. Contudo, "há uma potencial cisão entre o julgamento do próprio professor sobre, de um lado, o que

\footnotetext{
${ }^{4}$ Para maiores informações sobre o SIMAVE, poderá ser consultado sítio da Secretaria de Educação de Minas Gerais, disponível em: <http://www.simave.caedufj.net/>. Acesso em: 01 mar. 2018.
} 
significa uma boa prática e as necessidades dos estudantes e, de outro, o rigor da performance" (BALL, 2010, p. 42). Conforme afirma Ball (2010, p. 40):

(...) avaliações e classificações, postas dentro da competição entre grupos dentro das instituições, podem engendrar sentimentos individuais de orgulho, de culpa, de vergonha e de inveja - que tem uma dimensão emocional (status), assim como (a aparência de) racionalidade e objetividade.

Os resultados do SIMAVE, quando abaixo do esperado, podem provocar sentimento de culpa nos docentes. O mal-estar docente (ESTEVE, 1995), a sensação de incapacidade, de indignação e toda carga negativa pode se manifestar neste momento, caracterizado, muitas vezes, por um ambiente taxativo, ou seja, quando ocorrem trocas de acusações pelos resultados esperados.

Além do SIMAVE, como exemplo de responsabilização característica do modelo neoliberal, o estado de MG instituiu a ADI através da Lei Complementar no 71 de 30 de Julho de 2003. A $A^{5} I^{5}$ é um processo de avaliação dos servidores públicos estáveis ocupantes de cargos efetivos.

Conforme o regulamento, em caso satisfatório na ADI, passou a ser possível ao servidor público a promoção e progressão nas carreiras, e em caso insatisfatório, a não progressão. O mínimo de $70 \%$ foi adotado para a ADI. Os servidores que tivessem desempenho inferior a $70 \%$ não avançavam na carreira, sendo que os que tivessem desempenho inferior a $50 \%$ na ADI por dois anos consecutivos poderiam sofrer processo de exoneração. Dessa forma, substitui-se o tempo de serviço pelo desempenho.

A ADI, como instrumento regulador do Estado sobre os professores, provocou tensão no ambiente escolar, tendo em vista a pressão sobre os docentes para atingirem bons resultados: "Responsabilização e meritocracia são duas categorias, portanto, intimamente relacionadas" (FREITAS, 2012, p.386).

Não obstante, a qualidade do ensino está diretamente vinculada às condições de trabalho. Nesse sentido, de nada adianta cobrar qualidade sem criar condições reais, concretas para alcançá-la (RODRIGO; GALAN, 2010, p. 19). Em oposição à regulação exercida através da ADI, é possível questionar se as condições de trabalho oferecidas aos docentes estariam compatíveis com as metas que deveriam atingir.

Contudo, a implementação do programa CG na REE/MG pode ter colaborado para a precarização e intensificação do trabalho docente. Por precarização, concordamos com Sampaio e Marin (2004, p. 1203), ao afirmarem que:

\footnotetext{
${ }^{5}$ As leis complementares e decretos referentes à ADI, bem como os critérios adotados para avaliar os servidores, poderão ser consultas pelo sítio do Portal da Educação- Secretaria do Estado de Educação de MG. Disponível em: <http://seeavaliacaodesempenho.educacao.mg.gov.br/>. Acesso em 01 mar. 2018.
} 
Consideramos que problemas ligados à precarização do trabalho escolar não são recentes no país, mas constantes e crescentes, e cercam as condições de formação e de trabalho dos professores, as condições materiais de sustentação do atendimento escolar e da organização do ensino, a definição de rumos e de abrangência do ensino secundário e outras dimensões da escolarização, processo esse sempre precário, na dependência das priorizações em torno das políticas públicas.

Entre as condições precárias do trabalho docente da rede pública de ensino podemos citar a falta de recursos financeiros da escola para a compra de materiais necessários para o desenvolvimento das aulas, a ausência de infraestrutura adequada para o ensino, a extrema desigualdade social entre os alunos, a ausência de promoção de formação continuada para os docentes e baixa valorização do magistério. Isto tem se apresentado como um dos grandes entraves para a promoção da melhoria da educação no país.

Em relação à intensificação do trabalho docente, entendemos como ações que decorrem de um maior uso das capacidades físicas, cognitivas e emotivas do trabalhador, tendo por meta aumentar quantitativamente ou qualitativamente os resultados, ocasionando a degradação do seu trabalho (ROSSO, 2008; PINO, 2009; ASSUNÇÃO e OLIVEIRA, 2009).

\section{METODOLOGIA E JUSTIFICATIVA}

Este artigo, que é fruto de uma dissertação de mestrado, assume relevância acadêmica pelo fato de haver indícios, por meio de levantamento bibliográfico realizado (AUGUSTO, 2010, 2011, 2012; BARBOSA, 2013; DUARTE; OLIVEIRA, 2014), de intensificação e precarização do trabalho docente devido às medidas do programa de governo CG.

O levantamento bibliográfico foi realizado por meio de buscas de artigos científicos, dissertações de mestrado e teses de doutorado pelo Google Acadêmico, site de periódicos da Scielo, banco de teses da CAPES, Grupos de Trabalhos (GTs) da Associação Nacional de Pós-Graduação e Pesquisa em Educação (ANPEd) e na biblioteca do Centro Universitário Moura Lacerda, na cidade de Ribeirão Preto. A abordagem da pesquisa foi qualitativa. Para Minayo (1994, p. 22):

Quando se busca compreender processos educativos, trabalha-se com metodologias qualitativas, pois estas atendem a questões situadas no universo de significados, motivos, aspirações, crenças, valores e atitudes, um lado não perceptível e não captável em equações, médias e estatísticas. 
Após o levantamento bibliográfico, foram realizadas entrevistas semiestruturadas com cinco professores secundários de diferentes disciplinas que atuavam na REE/MG, no contexto do programa CG. As entrevistas foram gravadas e transcritas pelo próprio pesquisador. Ludke e André (1986, p.34) afirmam que "a grande vantagem da entrevista sobre outras técnicas é que ela permite a captação imediata e corrente da informação desejada, praticamente com qualquer tipo de informante e sobre os mais variados tópicos".

A seguir, serão apresentados alguns dos dados coletados. Os docentes foram identificados com a letra $\mathrm{D}$, de docente.

\section{AS PERCEPÇÕES DOS PROFESSORES SOBRE AS MANIFESTAÇÕES DO PROGRAMA CHOQUE DE GESTÃO}

Os docentes entrevistados afirmaram que o SIMAVE estava sendo uma forma de pressão para a busca por resultados.

Sim. O SIMAVE passou a ser uma referência para trabalharmos para poder obter resultado no fim do ano. Então a escola, ela precisa apresentar resultado, porque ela tem uma meta para poder cumprir e com isso a nós trabalhamos em cima do SIMAVE. É uma forma de nós apresentarmos resultados (D3).

Com certeza. Essa pressão, a cada ano que passa acaba sendo pior. Professores de Português e Matemática ainda mais, mas os outros conteúdos também contribuem para isso. Então, pressão tem sim (D4).

Tem essa pressão. Eu até acho que ela deveria acontecer sim (D5).

Na mesma perspectiva apresentada por Duarte (2011) sobre a busca que há por resultados escolares na REE/MG, fruto das medidas do CG e manifestada também por meio do SIMAVE, os docentes tiveram a percepção de que essa busca por resultados e metas a serem cumpridas tornou-se instrumento de pressão sobre o trabalho docente.

O docente D5 apresentou seu posicionamento sobre a pressão pela busca de resultados por meio do SIMAVE. Para ele, a pressão sobre os docentes por essa razão deve ocorrer sim. O posicionamento desse docente se opõe ao de Freitas (2007), que defende a tese de que as avaliações externas, por exemplo, o SIMAVE, deveriam ser instrumentos de monitoramento e não de pressão ou de responsabilização (accountability).

"A introdução de sistemas de avaliação profissional centrados no desempenho dos alunos, além de responsabilizar de sobremodo o professor, acaba por promover um intenso processo de desprofissionalização da carreira docente" (DUARTE, 2013, p.134). Além disso, a carga emotiva dos docentes é abalada ao sentirem-se pressionados a reverter a situação, ao passo que já não acreditam que seja possível. Assim como para Freitas (2007, 
p. 981), "Prova Brasil, SAEB e IDEB devem ser instrumentos de monitoramento de tendências e não instrumentos de pressão", o SIMAVE deveria ser um instrumento de diagnóstico ou monitoramento, mas o que se percebe é um instrumento de acusação e pressão sobre os docentes.

É possível que questões como a desigualdade social, os índices de analfabetismo dos pais dos alunos, a falta de infraestrutura nas escolas, a existência de alunos com necessidades especiais, entre outros fatores, não fossem considerados com a apresentação dos índices do SIMAVE. São fatores que deveriam ser considerados por influenciarem na assimilação do conhecimento conforme os padrões estabelecidos.

Toda a preocupação com os resultados do SIMAVE provocou um aumento da carga de trabalho dos docentes. Nesse sentido, em pesquisa realizada por Barbosa, (2013, p. 172) verificou-se que:

(...) uma das influências do SIMAVE no cotidiano escolar é em relação à demanda de trabalho. Dentre seus respondentes, $72 \%$ concordam que o SIMAVE aumentou a demanda de tarefas, em vista da necessidade de se preparar mais os alunos para os testes.

A elaboração de simulados para os alunos, gráficos, tabelas, formulários, participação em reuniões, planos de intervenção, estudo de descritores, entre tantos outros serviços, caracterizam a intensificação do trabalho docente na REE/MG a partir do SIMAVE. Como atesta Oliveira e Vieira (2012, p. 19) com relação ao estado de MG, "é o estado onde os docentes mais percebem o aumento das exigências sobre seu trabalho em relação ao desempenho dos alunos (70\%)".

É possível que a infraestrutura das escolas estaduais de MG não seja adequada para o trabalho dos docentes e a quantidade de alunos por turma também poderia estar implicando os resultados esperados. Desse modo, sobre a responsabilização, Freitas (2007, p. 975) defende que "a estratégia liberal é insuficiente porque responsabiliza apenas um dos polos: a escola", isentando o Estado das políticas públicas adotadas, enquanto Hypolito (2010, p. 1343) advoga que "o fracasso da qualidade da educação pública vem sendo atribuído por uma descentralização da culpa, que recai em última instância na responsabilização das escolas, do corpo docente, dos estudantes e pais". Os docentes explicam que:

A pressão vem de cima pra baixo. Vem a pressão da Secretaria da Educação, vem a pressão da Superintendência Regional de Ensino e mais perto de nós está a pressão do diretor da escola e do supervisor. Estes últimos querem bons resultados principalmente porque os bons resultados terão um rendimento, pois tem o prêmio no final do ano (D1). 
Sim, tanto que eles disponibilizam o seu material, oferecem pontos para quem faz prova. Deixa de fazer um provão para estar avaliando o SIMAVE. Essa pressão em cima. Sempre, sempre, cobrança da direção. Nós não podemos abaixar. Porque eles são cobrados também. É de cima para baixo, e o último patamar somos nós, os professores e os alunos que estão saindo fora da situação (D2).

A pressão vem de fora. Logicamente a direção de uma escola ela vai querer que o seu resultado apareça. Também, inclusive, há pressões no sentido de se a escola sai mal não vai receber isso, não vai receber aquilo. O prêmio, por produtividade. $E$ ainda digo, maquiado. É um prêmio maquiado. Tanto que a gente percebe que está sempre uma, uma... não sei se eu posso dizer isso... uma inversão. Quer dizer, uma hora está uma escola na ponta, outra hora outra. Não tá sempre a mesma escola na ponta (D5).

Os docentes possuem a percepção de que a pressão para a obtenção de resultados no SIMAVE ocorre do macro para o micro, ou seja, a direção escolar também é afetada pela pressão por resultados. O docente D5 aborda que os diretores, apesar de serem também pressionados, desejam bons resultados para utilizarem como marketing da sua escola. Isto revela que há uma competição entre as escolas da REE/MG no que tange ao ranking dos resultados do SIMAVE. Esta competição e avaliação pode gerar, como afirma Ball (2010) sentimentos individuais de orgulho e culpa, perante os resultados.

Os docentes D1 e D5 abordam que os resultados do SIMAVE implicarão o recebimento ou não do prêmio produtividade. Dentro dessa abordagem, o docente D5 denuncia que o prêmio produtividade nem sempre reflete os resultados reais das escolas, pois acredita que ele seja "maquiado". Para ele, a alternância de escolas nas primeiras colocações no ranking dos resultados do SIMAVE não condiz com a realidade do desempenho delas.

Fala que chama a atenção é a da docente D2, que aponta o oferecimento de pontos para os alunos ser uma das estratégias para que os alunos realizem as provas do SIMAVE.

Dentro dessa perspectiva, para o docente D5, o SIMAVE também é maquiado:

Eu acredito que também, a maioria dos resultados do SIMAVE são maquiados. Não respondem, não correspondem com a realidade do nosso ensino. Por exemplo, tem escolas que quando tem o SIMAVE, cadastram os melhores alunos, que são poucos, para fazer a prova do SIMAVE. Quer dizer, é uma amostragem não feita aleatoriamente. É uma amostragem. É realmente proposital. Isso é feito nas olimpíadas, isso é feito no SIMAVE, isso é feito no PROEB, isso é feito em todas as áreas, eu acho que em todas as áreas de ensino. Até mesmo no curso superior tem isso (D5).

A percepção desse docente revela que a oferta de pontos aos que realizassem o exame e a seleção dos melhores alunos para a realização das avaliações externas estaria entre as estratégias adotadas pelas escolas da REE/MG para obterem bons resultados. Constata-se que os gestores e docentes estariam em busca de estratégias para burlar o sistema que oferece sanções e recompensas. Esta possibilidade nos remete à teoria de Giroux (1997) sobre os professores como intelectuais transformadores. Ao entender os 
professores como intelectuais, e não como simples tarefeiros, compreende-se como se posicionam perante as imposições das políticas públicas estatais para a educação. Ao passo que não eram oferecidas condições de trabalho para os professores promoverem o ensino com a qualidade almejada, e eram pressionados por bons resultados no SIMAVE, criaram estratégias para contornar a situação.

Em relação a $A D I$, os entrevistados consideraram positiva, pois proporciona o crescimento profissional dos docentes, ao evitar que os mesmos se acomodem. Entretanto, os entrevistados D2 e D5 manifestaram-se contrários à forma como ela está sendo aplicada.

Não acredito em nada. Porque essa avaliação de desempenho seria atrelada ao salário. Então, por exemplo, se você tem uma avaliação de desempenho de $97 \%$, 97 pontos em 100, foi ótimo, não foi? E o outro professor teve uma avaliação de suponhamos, 80. Está bom, não está? Mas não tem nem um salário a mais, nem um "tostão" e reconhecimento, porque o reconhecimento nosso é o financeiro. Pelo menos se a escola fosse também reconhecida no sentido financeiro, entrasse verbas para poder fazer mais coisas, segundo o nosso resultado, tudo bem, mas não tem (D2).

Eu não vejo nem positiva nem negativa. Desde que se criou a avaliação do docente, até mesmo a autoavaliação, não vi, não vi melhora nenhuma em relação à isso. Eu não vi docente melhorando, porque existe uma avaliação, não vi escola melhorando porque existe essa avaliação (D5).

A performatividade implementada pelo Estado (BALL, 2004), em busca de níveis de desempenho, não promoveu a melhoria defendida nos discursos pautados na lógica neoliberal. A responsabilização e a meritocracia, que apenas penalizam o professor (FREITAS, 2010), manifestada na ADI, não possui resultado prático. Deste modo, por meio das percepções dos professores entrevistados, pressupõe-se que a ADI representa uma burocracia a mais na vida profissional dos docentes e não contribui de maneira alguma para a melhoria da qualidade na educação.

Quando foram indagados se percebiam que os alunos da REE/MG estavam sendo aprovados para o ano de ensino seguinte sem os conhecimentos necessários, foram unânimes em afirmar que sim.

Eu tenho certeza, porque a política do governo é a aprovação automática. Por isso tanta recuperação paralela bimestral. Chega ao final do ano, recuperação final e em janeiro mais outra recuperação. Fora que ainda pode ter os estudos autônomos de duas matérias (D2).

Porque reprovar é muito difícil. Você tem que aplicar tanta recuperação, tanta prova, e mais ainda, a pressão, para reprovar um aluno você tem que justificar tanto, sem contar que tem ano que você não pode reprovar. Chega lá um determinado ano, esse ano não vai ter reprovação para o 6ํㅡㄹ ano, não vai ter reprovação para o $3^{\circ}$ ano. Então você trabalha já sabendo que determinado ano você não pode reprovar o aluno (D3). 
Tendo que aplicar quatro recuperações bimestrais, uma recuperação final, uma nova oportunidade no mês de janeiro, com a possibilidade de o aluno ser aprovado para o ano de ensino seguinte com duas disciplinas pendentes, muitos docentes optam por aprová-los diretamente. $\mathrm{O}$ excesso de recuperações não garante que o conteúdo seja aprendido pelo aluno, uma vez que não há aulas efetivamente, e sim avaliações. Além disso, quando os alunos não estão com bom rendimento e se reprovam, a responsabilização paira sobre os professores e não sobre o sistema ou Estado (AUGUSTO, 2011).

Lecionar para alunos que não têm os conhecimentos necessários para o ano de ensino matriculado é um dos desafios para os docentes da REE/MG. Tal situação implica diretamente nas condições de trabalho deles, o que colabora também para a precarização do trabalho docente (OLIVEIRA, 2011).

Constatação realizada foi a de uma sobrecarga de trabalho para os docentes que atuam na REE/MG, acarretando uma intensificação do seu trabalho.

(...) o salário é muito baixo. Então os professores acabam trabalhando em várias escolas, em vários lugares ao mesmo tempo. Por isso a sobrecarga é muito grande, pois o trabalho fica mais complicado de ser tão bem feito como se ele trabalhasse em uma escola só (D1).

O número de horas que ele tem que trabalhar. Porque se ela tivesse, como eu já disse antes, um cargo, e tivesse tempo de pesquisa e não precisasse estar se desdobrando em outros cargos, aí sim eu acredito que nós teríamos uma educação de qualidade com profissionais qualificados (D2).

Acho que são muitas provas, muita recuperação, para a gente poder aplicar, corrigir. Cada ano que passa a carga de trabalho ela aumenta (D3).

Em conformidade com as constatações sobre as condições precárias e intensificadas do trabalho docente na REE/MG por Oliveira e Vieira (2012), para os docentes D1 e D2, o fato que mais tem colaborado para a sobrecarga de trabalho dos docentes é o de terem que trabalhar em mais de uma unidade educativa. Por serem mal remunerados, a maioria dos docentes da REE/MG trabalha também nas redes particulares ou municipais. Os cinco docentes entrevistados estavam nessa condição, o que acarreta mais tempo para itinerância, reuniões e eventos escolares.

O docente D3 considerou que o número excessivo de provas na REE/MG estaria colaborando para a sobrecarga de trabalho dos docentes. Considerando que durante um ano letivo há em média quatro testes, quatro provas específicas, quatro "provões", quatro recuperações bimestrais, duas recuperações finais e mais os trabalhos escolares, os docentes teriam que formular inúmeras questões e corrigi-las ao longo do período escolar. Destarte, os professores secundários da REE/MG estariam vivenciando um processo de 
intensificação e precarização do trabalho docente (OLIVEIRA E VIEIRA, 2012; OLIVEIRA, 2007; DUARTE, 2013).

Por fim, em consonância com os apontamentos de Brito (2013), sobre a remuneração dos docentes da REE/MG ser inferior à prevista pela lei do Piso Salarial dos professores, no âmbito nacional, todos os entrevistados concordaram que os docentes da REE/MG são mal remunerados.

\section{CONSIDERAÇÕES FINAIS}

$\mathrm{Na}$ educação mineira, o programa de governo CG, de tendências neoliberais, revelou-se como regulador, avaliador e performativo em relação aos professores secundários e as escolas do estado. Notou-se, neste contexto, o pedido de empréstimos financeiros ao Banco Mundial e semelhanças com as recomendações dessa instituição multilateral para a educação básica.

A responsabilização (accountability) e autorresponsabilização difundida no trabalho docente em decorrência dos índices apontados pelo SIMAVE provocaram um clima de tensão no ambiente escolar pela busca por bons resultados. Ao passo que o Prêmio Produtividade não contemplava a realidade da escola, sendo por isso, um sistema de premiação injusto.

A ADI foi percebida por três dos docentes como uma medida positiva, por estimular o crescimento profissional, enquanto para dois deles ela era indiferente em relação à qualidade na educação.

A sobrecarga de trabalho durante o período de vigência do CG, que contribuiu para a intensificação do trabalho docente, foi evidenciada pelo aumento da burocracia. O aumento do número de aplicações de provas, o elevado número de formulários para serem preenchidos, são exemplos atrelados à aplicação do SIMAVE e o preenchimento da ADI.

Os docentes da REE/MG receberam abaixo do Piso Salarial previsto por lei, tendo a política de subsídios congelado a carreira docente e estabelecido, na prática, um teto salarial. Devida à baixa remuneração, os docentes dividiam a jornada de trabalho em mais de uma unidade educativa, tendo sofrido com a itinerância e acúmulo de reuniões pedagógicas, o que elevava o processo de intensificação do trabalho docente.

Contudo, constatou-se que as medidas do programa CG, nas três gerações, provocaram uma intensificação e precarização do trabalho docente na REE/MG em virtude, principalmente, das condições de trabalho dos professores secundários, como a responsabilização por resultados, a má remuneração e a sobrecarga de trabalho. 


\section{REFERÊNCIAS}

ASSUNÇÃO, A. da Á.; OLIVEIRA, D. A.. Intensificação do Trabalho e Saúde dos Professores. Educação e Sociedade, Campinas, SP, v. 30, n. 107, p. 349-372, maio/ago. 2009. Disponível em: < http://www.scielo.br/pdf/es/v30n107/03.pdf>. Acesso em: 23 jan. 2017.

AUGUSTO, M. H. O. G.. Regulação educativa e trabalho docente em Minas Gerais: a obrigação de resultados. Educação e Pesquisa, São Paulo, v. 38, n. 03, p. 695-709, jul.set., 2012. Disponível em: < http://www.scielo.br/pdf/ep/v38n3/11.pdf>. Acesso em: 14 jan. 2017.

A regulação das políticas educacionais em Minas Gerais e a obrigação de resultados: o desafio da inspeção escolar. 2010. 279 f. Tese (Doutorado em Educação) Faculdade de Educação, Universidade Federal de Minas Gerais, Belo Horizonte, 2010. Disponível em: < http://www.bibliotecadigital.ufmg.br/dspace/bitstream/handle/1843/BUOS8DAMLM/tese__maria_helena_oliveira_gon_alves_augusto.pdf?sequence $=1>$. Acesso em: 01 mar. 2018.

A regulação educativa em Minas Gerais e efeitos sobre o trabalho docente. In: OLIVEIRA, Dalila Andrade; PINI, Mónica Eva; FELDFEBER, Myriam (org.). Políticas Educacionais e Trabalho Docente: Perspectiva Comparada. Belo Horizonte, MG: Fino Traço, 2011. Cap. 8, p. 171-186.

BALL, Stephen. Performatividade, privatização e o pós-estado do bem-estar. Educação \& Sociedade, v. 25, n. 89, p. 1105-1126, set.-dez., 2004. Disponível em: < http://www.scielo.br/pdf/es/v25n89/22613.pdf>. Acesso em: 01 mar. 2018.

Performatividades e fabricações na economia educacional: rumo a uma sociedade performativa. Educação e Realidade, Porto Alegre, RS, v. 35, n. 2, p. 37-56, maio/ago. 2010. Disponível em: < http://seer.ufrgs.br/index.php/educacaoerealidade/article/view/15865/9445>. Acesso em: 01 mar. 2018.

BANCO MUNDIAL. Priorities and strategies for education: a Word Bank sector review. Whashington D. C. 1995. Disponível em: < http://documents.worldbank.org/curated/pt/117381468331890337/pdf/multi-page.pdf>. Acesso em: 27 jul. 2018.

BARBOSA, L. C. de M.. O uso dos resultados do SIMAVE e suas possíveis implicações para gestores escolares e professores: $O$ caso das escolas públicas de Formiga-MG. 2013. 267 f. Dissertação (Mestrado em Educação)-Faculdade de Educação, Universidade Federal de Minas Gerais, Belo Horizonte, 2013. Disponível em: < 
http://www.bibliotecadigital.ufmg.br/dspace/bitstream/handle/1843/BUOS-

9AYK5D/liliane_dissertacao_fae.pdf?sequence=1>. Acesso em: 01 mar. 2018.

BRITO, V. L. F. A. Efeitos negativos do "choque de gestão na remuneração de professores em Minas Gerais. Fineduca, v. 3, n. 6, p. 1-20, RS, 2013. Disponível em: < http://seer.ufrgs.br/index.php/fineduca/article/view/57971>. Acesso em: 01 mar. 2018.

DUARTE, A. W. B.. Por que ser professor? Uma análise da carreira docente na educação básica no Brasil. 2013. 163 f. Dissertação (Mestrado em Educação)- Faculdade de Educação, Universidade Federal de Minas Gerais, Belo Horizonte, 2013. Disponível em: < http://www.bibliotecadigital.ufmg.br/dspace/bitstream/handle/1843/BUBD9Q5HTU/disserta_o__alexandre_william_barbosa_duarte.pdf?sequence=1>. Acesso em: 01 mar. 2018.

DUARTE, A. W. B.; OLIVEIRA, D. A.. Valorização profissional docente nos sistemas de ensino de Minas Gerais e Pernambuco. Práxis educacional, Vitória da Conquista, v. 10, n. 17, p. 67-97, jul./dez. 2014. Disponível em: <

http://www.gestrado.net.br/images/publicacoes/92/AlexandreDalila_ValorizacaoProfissiona IDocenteMGePE.pdf>. Acesso em: 01 mar. 2018.

ESTEVE, J. M.. Mudanças sociais e função docente. In: NÓVOA, António. Profissão professor. Porto: Porto Editora, 1995. p. 95-107.

FIDALGO, N. L. R.; FIDALGO, F.. Trabalho docente e a lógica produtivista: conformação e subjetividade. In: FIDALGO, F. et al. (orgs). A intensificação do trabalho docente: tecnologias e produtividade. Campinas, São Paulo: Papirus, 2009. 239 p.

FREITAS, L. C.. Eliminação adiada: o ocaso das classes populares no interior da escola e a ocultação da (má) qualidade do ensino. Educação e Sociedade, v. 28, n. 100-Especial, p.965-987, out., 2007.Disponível em: <

http://www.scielo.br/pdf/es/v28n100/a1628100.pdf>. Acesso em: 01 mar. 2018.

Os reformadores empresariais da educação: da desmoralização do magistério à destruição do sistema público de educação. Educação e Sociedade, Campinas, SP, v. 33, n. 119, p. 379-404, abr./jun.2012. Disponível em: < http://www.scielo.br/pdf/es/v33n119/a04v33n119.pdf>. Acesso em: 01 mar. 2018.

GIROUX, H.. Os professores como intelectuais. Porto Alegre: Artes Médicas, 1997.

HYPOLITO, A. M.. Reorganização Gerencialista da Escola e Trabalho Docente.

Educação: Teoria e Prática, v. 21, n. 38, p. 1-18, out./dez. 2011. Disponível em: < https://www.academia.edu/1546437/Reorganiza\%C3\%A7\%C3\%A3o_Gerencialista_da_E scola_e_Trabalho_Docente>. Acesso em: 01 mar. 2018. 
LUDKE, M.; ANDRÉ, M. E. D. A. Pesquisa em Educação: abordagens qualitativas. São Paulo: EPU, 1986.

MACIEL, R. M.; PREVITALI, F. S.. Impactos das Políticas Públicas do Trabalhador da Educação na Rede Estadual de Patos de Minas/MG em 2011. Revista LABOR, v.1, n. 6, p. 326-343, 2011. Disponível em:

<http://www.revistalabor.ufc.br/Artigo/volume6/7_IMPACTOS_DAS_POLITICAS_PUBLIC AS_DO_TRABALHADOR_DA_EDUCACAO_NA_REDE\%20_ESTADUUALDE_ENSINO_ DE_PATOS_DE_MINASMG_EM_2011.pdf>. Acesso em: 01 mar. 2018.

MACIEL, A. Governo de Minas faz empréstimo de R\$450 milhões para pagar dívidas com a Cemig. Em.com.br. Belo Horizonte. 28 nov. 2012. Política. Disponível em: < https://www.em.com.br/app/noticia/politica/2012/11/28/interna_politica,332637/governode-minas-faz-emprestimo-de-r-450-milhoes-para-pagar-divida-com-a-cemig.shtml>.

Acesso em: 27 jul. 2018.

MINAYO, M. C. S. Pesquisa social: teoria, método e criatividade. 24. ed. Petrópolis, RJ: Vozes, 1994.

OLIVEIRA, D. A.. Política educacional e a re-estruturação do trabalho docente: reflexões sobre o contexto latino-americano. Educação \& Sociedade, Campinas, v. 28, n. 99, p. 355-375, maio/ago., 2007. Disponível em: <

http://www.scielo.br/pdf/es/v28n99/a04v2899.pdf>. Acesso em: 01 mar. 2018.

A nova regulação de forças no interior da escola: carreira, formação e avaliação docente. Revista Brasileira de Política e Administração da Educação, v. 27, n.1, p.2538, jan./abr. 2011. Disponível em: < http://seer.ufrgs.br/index.php/rbpae/article/view/19917/11557>. Acesso em: 01 mar. 2018.

Das políticas de governo à política de Estado: reflexões sobre a atual agenda educacional brasileira. Educação e Sociedade, Campinas, SP, v. 32, n. 115, p. 323-337, abr./jun. 2011. Disponível em: < http://www.scielo.br/pdf/es/v32n115/v32n115a05.pdf>. Acesso em: 01 mar. 2018.

OLIVEIRA, D. A. e VIEIRA, L. M. F.. O trabalho docente na educação básica no estado de Minas Gerais: conhecendo novos docentes e suas condições. In.: DUARTE, Adriana et. al. (org.). $\mathbf{O}$ trabalho docente na educação básica em Minas Gerais. Belo Horizonte, MG: Fino Traço, 2012.

PINO, M. A. B. D. et al. Trabalho docente, controle e intensificação: câmeras, novo gerencialismo e práticas de governo. In: FIDALGO, Fernando et al. (orgs.). A intensificação do trabalho docente: tecnologias e produtividade. Campinas, São Paulo: Papirus, 2009. 239 p. 
RODRIGO, T.; GALAN, M. C. da S. Condições de trabalho e precarização do ensino médio público. Nucleus, Ituverava, SP, v. 7, n. 1, p. 11-24, abr. 2010. Disponível em: < http://www.nucleus.feituverava.com.br/index.php/nucleus/article/view/286/367>. Acesso em: 01 mar. 2018.

ROSSO, S. D.. Mais Trabalho! A intensificação do labor na sociedade contemporânea. São Paulo: Boitempo, 2008. 206 p.

SAMPAIO, M. das M. F. e MARIN, A. J.. Precarização do trabalho docente e seus efeitos sobre as práticas curriculares. Educação e Sociedade, Campinas, SP, v. 25, n. 89, p. 1203-1225, set/dez. 2004. Disponível em: < http://www.scielo.br/pdf/es/v25n89/22618>. Acesso em: 01 mar. 2018.

TORRES, R. M.. Melhorar a qualidade da educação básica? As estratégias do Banco Mundial. Trad. Mónica Corullón. In: DE TOMMASI, Lívia; WARDE, Mirian Jorge e HADDAD, Sérgio. O Banco Mundial e as políticas educacionais. São Paulo: Cortez, 1996. 